\title{
Vascular endothelial growth factor and insulin-like growth factor-1 in preterm infants with retinopathy of prematurity
}

Ali Peirovifar ${ }^{1}, \mathrm{MD}$, Manizheh Mostafa Gharehbaghi ${ }^{2}$,MD, Parvin Mostafa Gharabaghi ${ }^{3}$, MD, Karim Sadeghi ${ }^{4}$, MD

INTRODUCTION Retinopathy of prematurity (ROP) can lead to severe visual impairment. This study was conducted to determine the levels of biochemical mediators (i.e. vascular endothelial growth factor [VEGF] and insulin-like growth factor-1 [IGF-1]) in the blood of premature infants with proliferative ROP.

METHODS Blood samples from 71 preterm infants born at or before 32 weeks of gestation were obtained 6-8 weeks after birth. These infants were classified into two groups according to their eye examination results. The control group consisted of 41 infants who had no evidence of ROP, and the study group consisted of 30 infants with proliferative ROP at stage III or higher. Blood VEGF and IGF-1 levels were measured using enzyme-linked immunosorbent assay.

RESULTS The mean gestational ages of the infants at birth were $28.4 \pm 1.6$ and $28.8 \pm 1.6$ weeks in the study and control groups, respectively $(p=0.259)$. The mean postmenstrual age of the infants at the time of blood sampling was $34.9 \pm 1.2$ weeks in the study group and $34.6 \pm 1.3$ weeks in the control group $(p=0.339)$. The mean blood IGF-1 $(18.48 \pm 11.79 \mu \mathrm{g} / \mathrm{L}$ and $16.75 \pm 13.74 \mu \mathrm{g} / \mathrm{L}$ in the study and control groups, respectively; $p=0.580)$ and VEGF $(267.35 \pm 103.43 \mathrm{pg} / \mathrm{mL}$ and $237.52 \pm 130.92 \mathrm{pg} / \mathrm{mL}$ in the study and control groups, respectively; $\mathrm{p}=0.305)$ levels of the infants were not significantly different between the two groups.

CONCLUSION At 6-8 weeks after birth, blood IGF-1 and VEGF levels were not found to be significantly different between premature infants with proliferative ROP and those without.

Keywords: insulin-like growth factor, retinopathy of prematurity, vascular endothelial growth factor

\section{INTRODUCTION}

Retinopathy of prematurity (ROP) is a postnatal disorder of retinal vessels that develops in the incompletely vascularised retina of preterm infants. ${ }^{(1)}$ Only preterm infants whose retinal vessels have not yet completed centrifugal growth from the optic disk to the ora serrata may develop ROP. ${ }^{(2)}$ Although this disorder regresses in most patients, it can lead to severe visual impairment. ROP is a major cause of childhood blindness in both developing and developed countries, despite striking advances in neonatology. ${ }^{(3)}$ ROP is associated with excessive oxygen use in preterm newborn infants. ${ }^{(4)}$ It is a biphasic disease consisting of an initial phase of vessel loss followed by a second phase of vessel proliferation. ${ }^{(3-5)}$ It is clear that a growth factor, or several growth factors, regulated by hypoxia and hyperoxia is important in the development of ROP.(5) Vasculogenesis and angiogenesis are the results of a complex interaction between locally and systemically produced growth factors or mitogenes that stimulate or inhibit differentiation, proliferation, migration and maturation of endothelial cells. ${ }^{\left({ }^{6}\right)}$ It is increasingly difficult to ignore the roles of vascular endothelial growth factor (VEGF) and insulin-like growth factor-1 (IGF-1) in ROP. Initially thought to be a tumour-derived permeability enhancing factor, VEGF was later shown to be an endothelial cell mitogen. ${ }^{(6,7)}$ Studies with animal models support the central role of VEGF in ocular neovascularisation. ${ }^{\left({ }^{8}-10\right)}$ Clinical ROP is multifactorial - other biochemical mediators are also involved in the pathogenesis of retinopathy. Growth hormone and IGF-1 have been suspected to play a role in retinal neovascularisation, such as through control of VEGF activation. ${ }^{(11-13)}$ However, far too little attention has been paid to these markers in proliferative ROP. This study was performed to determine the levels of the biochemical mediators IGF-1 and VEGF in the blood of premature infants with proliferative ROP.

\section{METHODS}

We conducted this case-control study at the neonatal intensive care unit of a university teaching hospital between March 2009 and June 2010. Preterm infants born at or before 32 weeks of gestation were eligible for inclusion in this study. Infants with chromosomal anomalies or major congenital malformations were excluded from the study. The infants who met the inclusion criteria $(n=71)$ underwent initial and follow-up eye examinations by an ophthalmologist experienced in evaluating ROP. The initial eye examination was performed at the fourth

\footnotetext{
${ }^{1}$ Department of Anesthesiology, ${ }^{2}$ Women's Reproductive Health Research Center, Department of Pediatrics and Neonatology, ${ }^{3}$ Women's Reproductive Health Research Center, Department of Obstetrics and Gynecology, ${ }^{4}$ Department of Ophthalmology, Tabriz University of Medical Sciences, Tabriz, Iran 
Table I. Demographic characteristics of preterm infants.

\begin{tabular}{|c|c|c|c|}
\hline \multirow[t]{2}{*}{ Characteristic } & \multicolumn{2}{|c|}{ Mean \pm SD (range) } & \multirow[t]{2}{*}{ p-value } \\
\hline & Study group $(n=30)$ & Control group $(n=41)$ & \\
\hline Gestational age at birth (wks) & $28.4 \pm 1.6(26-32)$ & $28.8 \pm 1.6(26-34)$ & NS \\
\hline Birth weight (g) & $1120.0 \pm 196.0(780-1720)$ & $1189.0 \pm 454.0(800-1750)$ & NS \\
\hline Male* & $12(40.0)$ & $22(53.7)$ & NS \\
\hline Postmenstrual age at sampling (wks) & $34.9 \pm 1.2(33-37)$ & $34.6 \pm 1.3(33-38)$ & NS \\
\hline \multicolumn{4}{|l|}{ Apgar score } \\
\hline At $1 \mathrm{~min}$ & $4.8 \pm 1.4(2-7)$ & $6.5 \pm 1.4(2-9)$ & $<0.001$ \\
\hline At 5 mins & $7.2 \pm 1.4(3-9)$ & $8.4 \pm 1.3(6-10)$ & 0.001 \\
\hline
\end{tabular}

Table II. Respiratory support received by the preterm infants in the two groups.

\begin{tabular}{|c|c|c|c|}
\hline \multirow[t]{2}{*}{ Variable } & \multicolumn{2}{|c|}{ Mean \pm SD (range) } & \multirow[t]{2}{*}{ p-value } \\
\hline & Study group $(n=30)$ & Control group $(n=41)$ & \\
\hline No. of doses of surfactant* & $1.3 \pm 0.7$ & $1.5 \pm 1.1$ & NS \\
\hline Need for $\mathbf{M V}^{+}$ & $9(30.0)$ & $9(22.0)$ & NS \\
\hline \multicolumn{4}{|c|}{ Duration of respiratory support (days) } \\
\hline MV & $7.5 \pm 4.2(3-20)$ & $3.5 \pm 0.5(2-6)$ & 0.006 \\
\hline CPAP & $4 \pm 1.7(2-9)$ & $2.6 \pm 0.4(1-5)$ & 0.043 \\
\hline Oxygen supplementation & $27.7 \pm 11.9(7-54)$ & $28.9 \pm 5.4(7-47)$ & NS \\
\hline
\end{tabular}

${ }^{*}$ Range is not presented here. ${ }^{\dagger}$ Data is presented as no. (\%). CPAP: continuous positive airway pressure; MV: mechanical ventilation; NS: not statistically significant; SD: standard deviation

week after birth. The opthalmologist recommended follow-up eye examinations where necessary, based on the retinal findings, which were classified according to international standards of classification. ${ }^{(13)}$ All preterm infants with ROP stage III or higher at the follow-up eye examination were assigned to the study group ( $n=30$ ), while preterm infants with normal eye examination results at 6-8 weeks after birth were included in the control group $(n=41)$. The ethics committee of the university approved the study. Written informed parental consent was also obtained in all cases.

Blood samples were collected at the time of follow-up eye examination, which was at 6-8 weeks after birth. The samples were centrifuged at 3,000 rpm and stored at $-70^{\circ} \mathrm{C}$. Laboratory analysis was blinded to the infant groups. IGF-1 and VEGF levels were measured by quantitative sandwich enzymelinked immunosorbent assay (ELISA) using IDS IGF-1 (AC27F1; Immunodiagnostic Systems Ltd, Boldon, UK) and IBL ELISA kits (27171; Medical \& Biological Laboratories Co Ltd, Nagoya, Japan) for IGF-1 and VEGF measurement, with sensitivity of $3.1 \mu \mathrm{g} / \mathrm{L}$ and $1.01 \mathrm{pg} / \mathrm{mL}$, respectively. Statistical analysis was performed using the Statistical Package for the Social Sciences version 15 (SPSS Inc, Chicago, IL, USA). Categorical variables were evaluated using chi-square and Fisher's exact tests. Continuous variables were compared using either $t$-test (for normally distributed data) or Mann-Whitney $U$-test (for data with a skewed distribution). A p-value of $<0.050$ was considered statistically significant.

\section{RESULTS}

We included 71 preterm newborn infants in this study, out of which 30 were diagnosed with proliferative ROP (i.e. the study group) and 41 had normal ophthalmologic examinations (i.e. the control group). The demographic characteristics of the infants in the two groups are shown in Table I.

The study group's Apgar scores at 1 and 5 mins after birth were significantly lower than those in the control group $(p<0.001$ and $p=0.001$, respectively). Surfactant replacement therapy was done for $11(26.8 \%)$ infants in the control group and 15 $(50 \%)$ infants in the study group $(p=0.045)$. The two groups were significantly different with regard to the need for surfactant replacement therapy, duration of mechanical ventilation, and respiratory support requirements (Table II). Blood transfusion was done in 17 (56.7\%) and 19 (46.3\%) infants in the study and control groups, respectively $(p=0.390)$. Sepsis was diagnosed in $5(16.7 \%)$ and $2(4.9 \%)$ infants in the study and control groups, respectively $(p=0.125)$.

The mean blood levels of IGF-1 in the study and control groups were $18.48 \pm 11.79$ (95\% confidence interval [CI] 14.1-22.9) $\mu \mathrm{g} / \mathrm{L}$ and $16.75 \pm 13.74(95 \% \mathrm{Cl} 12.4-21.1) \mu \mathrm{g} / \mathrm{L}$, respectively $(p=0.580)$. The mean blood levels of VEGF in the study and control groups were $267.35 \pm 103.43(95 \% \mathrm{Cl}$ 228.9-511.5) pg/mL and $237.52 \pm 130.92$ (95\% Cl 196.2278.8) $\mathrm{pg} / \mathrm{mL}$, respectively $(\mathrm{p}=0.305)$. The mean levels of the studied biochemical markers in the preterm infants are shown in Table III.

Diode laser photocoagulation was performed in 21 infants with threshold ROP. Mean IGF-1 levels in infants of different postmenstrual ages is showed in Table IV.

\section{DISCUSSION}

ROP is an important cause of blindness in both developed and developing countries. ${ }^{(3)}$ World Health Organization's 
Table III. Level of biochemical markers in the preterm infants in the two groups.

\begin{tabular}{|c|c|c|c|c|c|}
\hline \multirow[t]{2}{*}{ Parameter } & \multicolumn{2}{|c|}{ Study group $(n=30)$} & \multicolumn{2}{|c|}{ Control group $(n=41)$} & \multirow[t]{2}{*}{ p-value } \\
\hline & Mean \pm SD & $95 \% \mathrm{Cl}$ & Mean \pm SD & $95 \% \mathrm{Cl}$ & \\
\hline IGF-1 $(\mu \mathrm{g} / \mathrm{L})$ & $18.48 \pm 11.79$ & $14.1-22.9$ & $16.75 \pm 13.74$ & $12.4-21.1$ & 0.580 \\
\hline VEGF $(\mathrm{pg} / \mathrm{mL})$ & $267.35 \pm 103.43$ & $228.9-511.5$ & $237.52 \pm 130.92$ & $196.2-278.8$ & 0.305 \\
\hline
\end{tabular}

$\mathrm{Cl}$ : confidence interval; IGF-1: insulin-like growth factor-1; SD: standard deviation; VEGF: vascular endothelial growth factor

Table IV. IGF-1 levels of the preterm infants according to different postmenstrual ages.

\begin{tabular}{|c|c|c|c|c|c|}
\hline \multirow{2}{*}{$\begin{array}{l}\text { Postmenstrual } \\
\text { age (wks) }\end{array}$} & \multicolumn{2}{|c|}{ Study group $(n=30)$} & \multicolumn{2}{|c|}{ Control group $(n=41)$} & \multirow{2}{*}{$\begin{array}{l}\text { Total no. } \\
(n=71)\end{array}$} \\
\hline & IGF-1* $(\mu \mathrm{g} / \mathrm{L})$ & No. of patients & IGF-1* ( $\mu \mathrm{g} / \mathrm{L})$ & No. of patients & \\
\hline 33 & $19.52 \pm 13.43$ & 4 & $13.4 \pm 6.69$ & 7 & 11 \\
\hline 34 & $16.76 \pm 12.74$ & 6 & $19.94 \pm 14.31$ & 15 & 21 \\
\hline 35 & $20.87 \pm 13.68$ & 12 & $20.18 \pm 17.10$ & 12 & 24 \\
\hline 36 & $16.54 \pm 9.34$ & 5 & $7.7 \pm 5.22$ & 4 & 9 \\
\hline 37 & $14.16 \pm 7.21$ & 3 & 5.4 & 1 & 4 \\
\hline 38 & - & - & $7.7 \pm 10.88$ & 2 & 2 \\
\hline
\end{tabular}

*Data is presented as mean \pm standard deviation. IGF-1: insulin-like growth factor-1

VISION 2020 programme delineates ROP as a preventable disease that requires early detection and treatment to prevent blindness and reduce inherent costs to the individual and community. ${ }^{(14)}$ It has been long believed that oxygen therapy leads to an increased risk of ROP in preterm infants. ${ }^{(2)}$ However, ROP can occur even with careful use of oxygen. ${ }^{(4)}$ Several factors increase the risk of ROP, including low gestational age, low birth weight, sepsis, intraventricular haemorrhage, blood transfusion and mechanical ventilation. ${ }^{(15,16)}$ In our study, we found lower Apgar scores and severe respiratory distress (which manifested as a need for surfactant replacement therapy), longer assisted ventilation and use of continuous positive airway pressure to be significantly more common in infants who developed proliferative ROP. Our findings concur with the findings in a study by Karna et al. ${ }^{(15)}$

With respect to the pathogenesis of ROP, inhibition of vascularisation in the early phase of ROP has been attributed to the hypoxic suppression of VEGF. A lack of IGF-1 in this phase of ROP may also prevent normal retinal vascular growth. In phase II of ROP, pathologic vascular proliferation appears to be associated with rising levels of VEGF and IGF-1 induced by hypoxia. ${ }^{(3,5,17,18)}$ Several studies have also assessed IGF-1 and VEGF so as to define their role in the pathogenesis of ROP. ${ }^{(17-25)}$ Different studies have yielded different results - this may be due to variations in study design, the wide range of gestational ages and postnatal ages of study groups, different sample sizes and different stages of ROP. A study by PérezMuñuzuri et $\mathrm{al}^{(17)}$ showed reduced IGF-1 levels in infants who developed ROP ( $n=3$ ) three weeks postpartum, independent of gestational age at birth; a rapid rise in IGF-1 levels between the third and fifth weeks postpartum appeared to be related to progression to a higher stage of ROP. Only three patients with proliferative ROP were included in Pérez-Muñuzuri et al's study. ${ }^{(17)}$

In another study, elevated VEGF and reduced IGF-1 levels were reported in infants with ROP, though the severity of
ROP was specified. ${ }^{(18)}$ Hellström et al ${ }^{(26)}$ conducted a study measuring serum IGF-1 levels weekly and showed that low serum IGF-1 levels correlated with a later development of ROP. Hellström et al also concluded that the mean IGF-1 level at postmenstrual weeks 30 to 33 is a predictive factor of ROP that is as important as the degree of prematurity. ${ }^{(26)}$ In our study, there was no statistically significant difference in IGF-1 and VEGF levels between preterm infants with proliferative ROP and those without at 6-8 weeks after birth. This lack of significant difference in VEGF and IGF-1 levels in the present study could be due to the higher postnatal and postmenstrual ages of our cohort at sampling. IGF-1 level is known to be affected by gestational age, birth weight, protein intake and stage of retinopathy. ${ }^{(18-20)}$ In our study, most of the infants in the study group were in the proliferative phase of ROP at sampling. In the more severe stages of ROP (at 6-8 weeks after birth), the blood levels of IGF-1 and VEGF reach levels not different from those in infants without ROP.

Our study has some limitations, such as the small cohort of infants. As there was a lack of serial measurement of biochemical markers, we could not show the variations in these parameters over time. However, an advantage of our study is that ophthalmologic examinations were performed consistently and all infants were seen by the same ophthalmologist for the entire duration of the study.

In conclusion, our data demonstrated that at 6-8 weeks after birth, the blood levels of IGF-1 and VEGF were not significantly different between premature infants with proliferative ROP and those without.

\section{REFERENCES}

1. Phelps DL. Retinopathy of Prematurity. In: Martin RJ, Fanaroff AA, Walsh MC, eds. Fanaroff \& Martin's Neonatal-Perinatal Medicine: Diseases of the Fetus and Infant. Vol 19 th ed. Missouri: Elsevier Mosby, 2011: 1764-9.

2. Phelps DL. Retinopathy of prematurity: history, classification and pathophysiology. Neoreviews 2001; 2:e153-166.

3. Askin DF, Diehl-Jones W. Retinopathy of prematurity. Crit Care Nurs Clin North Am 2009; 21:213-33. 
4. Wright KW, Sami D, Thompson L, et al. A physiologic reduced oxygen protocol decreases the incidence of threshold retinopathy of prematurity. Trans Am Ophthalmol Soc 2006; 104:78-84.

5. Chen J, Smith LE. Retinopathy of prematurity. Angiogenosis 2007; 10:133-40.

6. Senger DR, Galli SJ, Dvorak AM, et al. Tumor cells secrete a vascular permeability factor that promotes accumulation of ascites fluid. Science 1983; 219:983-5.

7. Plate $\mathrm{KH}$, Breier G, Weich HA, Risau W. Vascular endothelial growth factor is a potential tumor angiogenesis factor in human gliomas in vivo. Nature 1992; 359:845-8.

8. Adamis AP, Shima DT, Tolentino MY, et al. Inhibition of vascular endothelial growth factor prevents retinal ischemia - associated iris neovascularization in a nonhuman primate. Arch Opthalmol 1996; 114:66-71.

9. Reichelt M, Shi S, Hayes M, et al. Vascular endothelial growth factor-B and retinal vascular development in the mouse. Clin Experiment Ophthalmol, 2003; 31:61-5.

10. Leske DA, Wu J, Fautsch MP, et al. The role of VEGF and IGF-1in a hypercarbic oxygen-induced retinopathy rat model of ROP. Mol Vis 2004; 10:43-50.

11. Hellstrom A, Perruzzi C, Ju M, et al. Low IGF-1 suppresses VEGFsurvival signaling in retinal endothelial cell: direct correlation with clinical retinopathy of prematurity. Proc Natl Acad Sci U S A 2001; 98:5804-8.

12. Smith LE, Shen W, Perruzzi C, et al. Regulation of vascular endothelial growth factor-dependent retinal neovascularization by insulin-like growth factor-1 receptor. Nat Med 1999; 5:1390-5.

13. International Committee for the Classification of Retinopathy of Prematurity. The International Classification of Retinopathy of Prematurity revisited. Arch Ophthalmol 2005; 123:991-9.

14. Gilbert C, Foster A. Childhood blindness in the context of VISION 2020 - the right to sight. Bull World Health Organ 2001; 79:227-32.

15. Karna P, Muttineni J, Angell L, Karmaus W. Retinopathy of prematurity and risk factors: a prospective cohort study. BMC Pediatr 2005; 5:18.
16. Romgagnoli C. Risk factors and growth factors in ROP. Early Hum Dev 2009; 85:s79-82.

17. Pérez-Muñuzuri A, Fernández-Lorenzo JR, Couce-Pico ML, Blanco-Teijeiro MJ, Fraga-Bermúdez JM. Serum levels of IGF-1 are a useful predictor of retinopathy of prematurity. Acta Paediatr 2010; 99:519-25.

18. Villegas-Becerril E, González-Fernández R, Perula-Torres L, GallardoGalera JM. [IGF-I, VEGF and bFGF as predictive factors for the onset of retinopathy of prematurity (ROP)]. Arch Soc Esp Oftalmol 2006; 81:641-6. Spanish.

19. Engström E, Niklasson A, Wikland KA, Ewald U, Hellström A. The role of maternal factors, postnatal nutrition, weight gain, and gender in regulation of serum IGF-I among preterm infants. Pediatr Res 2005; 57:605-10.

20. Kielczewski JL, Jarajapu YP, McFarland EL, et al. Insulin-like growth factor binding protein-3 mediates vascular repair by enhancing nitric oxide generation. Circ Res 2009; 105:897-905.

21. Pau H. Hypothesis on the pathogenesis of retinopathy of prematurity - it is not VEGF alone but anatomical structures that are crucial. Graefes Arch Clin Exp Ophthalmol 2010; 248:1-3.

22. Budd SI, Hartnett ME, Increased angiogenic factors associated with peripheral avascular retina and intraviterous neovascularization: a model of retinopathy of prematurity. Arch Ophthalmol 2010; 128:589-95.

23. Yingchuan F, Chuntao L, Hui C, Jianbin H. Increased expression of TGFbeta 1 and Smad 4 on oxygen-induced retinopathy in neonatal mice. Adv Exp Med Biol 2010; 664:71-7.

24. Sonmez K, Drenser KA, Capone A Jr, Trese MT. Viterous levels of stromal cell-derived factor 1 and vascular endothelial growth factor in patients with retinopathy of prematurity. Ophthalmology 2008; 115:1065-1070.e1.

25. Machalińska A, Modrzejewska M, Dziedziejko V, et al. [Evaluation of VEGF and IGF-1 plasma levels in preterm infants - potential correlation with retinopathy of prematurity, clinical implications]. Klin Oczna 2009; 111:302-6. Polish.

26. Hellström A, Engström E, Hård AL, et al. Postnatal serum insulin-like growth factor I deficiency is associated with retinopathy of prematurity and other complications of premature birth. Pediatrics 2003; 112:1016-20. 